\title{
Synthesis of Copper Oxide Nanoparticles Using Plant Leaf Extract of Catha edulis and Its Antibacterial Activity
}

\author{
Worku Wubet Andualem, ${ }^{1}$ Fedlu Kedir Sabir, ${ }^{2}$ Endale Tsegaye Mohammed, ${ }^{3}$ \\ Hadgu Hailekiros Belay, ${ }^{2}$ and Bedasa Abdisa Gonfa $\mathbb{D}^{2}$ \\ ${ }^{1}$ Arba Minch University, College of Natural Sciences, Department of Chemistry, P. O. Box: 21, Arba Minch, Ethiopia \\ ${ }^{2}$ Adama Science and Technology University, School of Applied Natural Science, Departments of Applied Chemistry, \\ P. O. Box:1888, Adama, Ethiopia \\ ${ }^{3}$ Hawassa University, College of Natural and Computational Science, Department of Chemistry, P. O. Box: 05, Hawassa, Ethiopia
}

Correspondence should be addressed to Bedasa Abdisa Gonfa; bedassa.abdissa@astu.edu.et

Received 16 April 2020; Revised 20 August 2020; Accepted 6 November 2020; Published 24 November 2020

Academic Editor: María J. Lázaro

Copyright (c) 2020 Worku Wubet Andualem et al. This is an open access article distributed under the Creative Commons Attribution License, which permits unrestricted use, distribution, and reproduction in any medium, provided the original work is properly cited.

\begin{abstract}
Development of green technology is generating interest of researchers towards ecofriendly and low-cost methods for biosynthesis of nanoparticles (NPs). In this study, copper oxide $(\mathrm{CuO}) \mathrm{NPs}$ were synthesized using a copper nitrate trihydrate precursor and Catha edulis leaves extract as a reducing and capping agent during the synthesis. The biosynthesized CuO NPs were characterized using an X-ray diffractometer (XRD), scanning electron microscopy-energy-dispersive X-ray spectroscopy (SEM-EDS), transmission electron microscope (TEM), Ultraviolet visible spectroscopy (UV-Vis), and Fourier transform infrared (FTIR) spectroscopy. XRD characterization confirmed that the biosynthesized $\mathrm{CuO}$ NPs possessed a good crystalline nature which perfectly matched the monoclinic structure of bulk CuO. Furthermore, the results obtained from SEM and TEM showed that the biosynthesized $\mathrm{CuO}$ NPs were spherical in shape. EDS characterization of the biosynthesized NPs also indicated that the reaction product was composed of highly pure $\mathrm{CuO}$ NPs. Moreover, the antimicrobial activities of different concentrations of CuO NPs synthesized using Catha edulis extract were also tested. Accordingly, the result showed that the highest zone of inhibitions measured were for $\mathrm{CuO} \mathrm{NPs} \mathrm{synthesized} \mathrm{using} 1: 2$ ratios at $40 \mathrm{mg} / \mathrm{ml}$ solution concentration and observed to be $22 \pm 0.01 \mathrm{~mm}$, $24 \pm 0.02 \mathrm{~mm}, 32 \pm 0.02 \mathrm{~mm}$, and $29 \pm 0.03 \mathrm{~mm}$ for S. aureus, S. pyogenes, E. coli, and K. pneumonia, respectively.
\end{abstract}

\section{Introduction}

The emergence of infectious diseases in general causes a serious threat to public health worldwide especially with the emergence of antibiotic-resistant strains of bacteria. Grampositive and Gram-negative bacterial strains are considered as presenting a major public health problem, and as a result, antibiotics have been used to control infections resulting from community and hospital settings [1]. With the emergence of microorganisms resistant to multiple antimicrobial agents, there is a growing interest in developing new bactericides based on inorganic materials to substitute the traditional organic agents as organic agents have limited applications due to their low heat resistance, high decomposability, and short life $[2,3]$. Nowadays, metal oxide nanoparticles (NPs) such as copper oxide $(\mathrm{CuO})$, iron oxide $\left(\mathrm{Fe}_{3} \mathrm{O}_{4}\right)$, and zinc oxide $(\mathrm{ZnO})$ have drawn attention due to their unique optical, physical, and biological properties [4-6]. Among these metal oxide NPs, CuO NPs have become a focus of interest because they play a significant role in environmental remediation and biopharmaceutical industries [7]. CuO NPs can be synthesized using various physical and chemical methods such as electrochemical reduction $[8,9]$, sonochemical methods [10-12], chemical precipitation [8], solution plasma, thermal decomposition [11], microwave irradiation [13], and the sol-gel method [14-16]. Even though these synthesis methods of NPs are easy and provide high yields, the use of toxic chemicals as reducing agents remains a major concern. In certain methods, the use of nonpolar solvents for the synthesis of $\mathrm{CuO}$ NPs amplifies 
the toxicity of the NPs. Therefore, utilizing biological sources for the synthesis of NPs could provide a favorable, nontoxic, and ecofriendly approach [17].

Biological methods of synthesis of NPs using microorganisms such as algae, fungi, bacteria, and plant leaves extracts have been suggested as possible ecofriendly alternatives to chemical methods as these methods are of low cost, energy efficient, and nontoxic [18]. Use of plant extracts for synthesis of NPs could be advantageous over other environmentally benign biological processes as this eliminates the elaborate process of maintaining cell culture [19]. Furthermore, the advantage of using plants for the synthesis of NPs is that they are easily available, safe to handle, and possess a broad variability of metabolites that may aid in reduction [20].

Based on the previous literature reports, $\mathrm{CuO}$ NPs were synthesized from various plants extracts such as Acalypha indica [21], Phyllanthus amarus [22], Terminalia arjuna [23], Calotropis gigantean [24], Malva sylvestris [25], Cassia alata [26], Gloriosa superba [2], and Carica papaya [27], and their antimicrobial activities were also reported.

In the present study, Catha edulis leaves extracts were considered for the synthesis of nanoparticles as this is the first ever detailed report on the plant being utilized for green synthesis of NPs. Catha edulis, commonly known as khat, qat, chat, or miraa, is a small-to-medium-sized evergreen tree that belongs to the Celastraceae family [28]. Some oral traditions claim that khat originated from Yemen; however, the literature report indicates that khat originated from Ethiopia, specifically in Hararghe, with a gradual expansion to different parts of Ethiopia, Yemen, and other parts of the world [29]. The leaves of this small tree are chewed by millions worldwide as a mild, amphetamine-like psychostimulant drug [30]. The chemical constituents of Khat include alkaloids, terpenoids, flavonoids, sterols, glycosides, tannins, amino acids, vitamins, and minerals [30, 31]. Studies have indicated that biomolecules such as proteins, phenols, and flavonoids not only play a role in reducing the ions to nanosize but also play an important role in the capping of NPs [32]. Therefore, this work aimed to explore the application of Catha edulis leaves extract as a capping and reducing agent for the synthesis of $\mathrm{CuO}$ NPs in addition to its consumption as amphetamine-like psychostimulant drug worldwide and evaluate the antibacterial activities of the synthesized $\mathrm{CuO}$ NPs against selected pathogenic organisms using the agar disc diffusion method. Furthermore, this work opens up a door for further explorations on many of Ethiopian-origin plants for nanomaterial synthesis which could be used for various applications.

\section{Materials and Methods}

2.1. Biosynthesis of CuO Nanoparticles. Fresh leaves of Catha edulis were collected from rural farm areas and washed with distilled water to remove the dust particles. The cleaned leaves were dried for 7 days at room temperature under shade and then ground into a fine powder using a mortar. $10 \mathrm{~g}$ of Catha edulis powder was taken for extraction purpose and boiled with $150 \mathrm{~mL}$ of distilled water for $30 \mathrm{~min}$ at $80^{\circ} \mathrm{C}$, and the color of the aqueous solution was changed from watery to light brown. The extract was cooled at room temperature and filtered by using Whatman No 1 filter paper. Then, three different samples with different precursor salt to Catha edulis extract ratios $(\mathrm{w} / \mathrm{v})$ were prepared by taking different weights of the salt precursor and volume of Catha edulis leaf extract using a previously developed procedure [2]. Accordingly, three $100 \mathrm{~mL}$ Catha edulis leaf extracts were added into three different volumetric flasks and heated to a temperature of $80^{\circ} \mathrm{C}$ while stirring using a magnetic stirrer. After the solution temperature of the extract reached $80^{\circ} \mathrm{C}, 10,30$, and $50 \mathrm{~g}$ of copper (II) nitrate trihydrate (UNI-CHEM Chemical Reagents) precursor salt were added to the first, second, and third leaf extracts, respectively. The three samples were, then, labeled as $1: 10$ (10 g: $100 \mathrm{ml}), 3: 10$ (30 g: $100 \mathrm{ml})$, and $1: 2(50 \mathrm{~g}: 100 \mathrm{ml})$ ratios, respectively. Then, for each sample, the mixture was stirred continuously using a magnetic stirrer at $80^{\circ} \mathrm{C}$ until the color was changed from deep green to deep brown and precipitate was observed. The precipitate of each sample was, then, centrifuged at $1000 \mathrm{rpm}$ for $30 \mathrm{~min}$ and washed with deionized water to remove impurities and centrifuged again for $20 \mathrm{~min}$. Finally, each precipitate was dried in an oven at $150^{\circ} \mathrm{C}$ for $3(1 / 2) \mathrm{hrs}$ and was ground to a fine powder using an agate mortar. The black powder obtained from the abovementioned method was calcinated at $400^{\circ} \mathrm{C}$ for $2 \mathrm{hrs}$.

2.2. Characterization of Biosynthesized CuO Nanoparticles. The morphology and composition of the synthesized $\mathrm{CuO}$ NPs were characterized by field emission scanning electron microscopy (FE-SEM, JEOL-JSM 6500F, made in Japan), FESEM coupled energy-dispersive X-ray spectroscopy (EDX), and a transmission electron microscope (HR-TEM, Tecnai F20 G2, Philips, the Netherlands). Crystalline structure and the average crystalline size of the synthesized $\mathrm{CuO}$ NPs were characterized using an X-ray diffractometer (XRD-7000, Shimadzu Co., Japan) equipped with a Cu target for generating a $\mathrm{Cu} \mathrm{K} \alpha$ radiation with $(\lambda=1.54056 \AA)$. XRD spectra were recorded from $10^{\circ}$ to $80^{\circ}$ with $2 \theta$ angles using $\mathrm{CuK} \alpha$ radiation operated at $40 \mathrm{kV}$ and $30 \mathrm{~mA}$. The optical absorption spectra of the synthesized $\mathrm{CuO}$ NPs were recorded using a UV/Vis (JASCO V-670UV-Vis spectrophotometer equipped with a diffuse reflectance attachment for powder samples) spectrophotometer. For functional groups analysis, the Fourier transform infrared (FTIR) spectrum was recorded using the Perkin Elmer 65 in the range of $4000-400 \mathrm{~cm}^{-1}$.

2.3. Antibacterial Activity Analysis of Biosynthesized $\mathrm{CuO}$ NPs. In vitro antibacterial activity for different concentrations of the biosynthesized $\mathrm{CuO}$ NPs and crude extract of Catha edulis against Gram-positive (Staphylococcus aureus (ATCC25923) and Streptococcus pyogen (ATCC700603)) and Gram-negative (Klebseilla pneumonia (ATCC 19615) and Escherichia coli (ATCC 25922)) bacterial strains was tested by the disc diffusion method. These bacterial strains were cultured and obtained from the Oromia Region Health Bureau regional laboratory, Adama, Ethiopia. All the 
bacterial strains were maintained at $4^{\circ} \mathrm{C}$ on nutrient agar slants. The bioassay used was the standard disk diffusion assay on Mueller Hilton Agar Media [33, 34]. Test disks were prepared by dipping and saturating sterilized filter paper discs in the test suspensions. All the Petri dishes were sealed with the sterile laboratory parafilm to avoid eventual evaporation of the test samples. A standard commercial Gentamicin was used as positive control, and discs impregnated with DMSO was used as negative control. The plates were incubated at $37^{\circ} \mathrm{C}$ overnight in an incubator and were shaken gently to allow even mixing of bacteria cells and agar. Then, 20 and $40 \mathrm{mg}$ from each of the three ratios of CuO NPs $(1: 10,3: 10$, and $1: 2)$ were taken and dissolved in $1 \mathrm{~mL}$ of DMSO to obtain 20 and $40 \mathrm{mg} / \mathrm{mL}$ solutions. From each different ratio, $100 \mu \mathrm{L}$ was taken and saturated with discs (5-6 mm diameter) and incubated at $37^{\circ} \mathrm{C}$ for about $24 \mathrm{hrs}$. In antibacterial testing against each strain, triplicate measurements were performed and the average value was used in reporting the results.

\section{Results and Discussion}

3.1. Thermal Gravimetric Analysis (TGA). The as-synthesized $\mathrm{CuO}$ NPs using copper nitrate trihydrate precursor salt and Catha edulis leaves extract were characterized by using TGA/DTA. The weight losses of the investigated materials were analyzed. Figure 1 shows the thermo gravimetric analysis and differential thermal analysis of the as-synthesized $\mathrm{CuO}$ NPs.

The TGA curve shows mass loss of the sample, whereas the DTA curve indicates the energy gain or loss during the process. As it can be observed from Figure 1, the TGA curve of $\mathrm{CuO}$ NPs showed three-step decomposition, and weight losses were observed in the temperature ranges of $25-150^{\circ} \mathrm{C}$, $400-600^{\circ} \mathrm{C}$, and $601-1000^{\circ} \mathrm{C}$. The weight loss of the material observed in the temperature range of $25-150^{\circ} \mathrm{C}$ was about $11.594 \%$, and this was mainly due to vaporization of water content from the sample. The sample also showed a weight loss of about $1.35 \%$ in the temperature range of $400-600^{\circ} \mathrm{C}$ that could be due to combustion of biomolecules from the Catha edulis extract that remained in the biosynthesized NPs. The weight loss observed above $600^{\circ} \mathrm{C}$ was about $2.626 \%$ that may be due to escaping of oxygen from the sample [19]. In general, from TGA analysis, the total weight loss calculated was $15.570 \%$, and the TGA results suggested that this compound is thermally stable and it has negligible weight loss when compared to the bulk sample of CuO NPs.

3.2. X-Ray Diffraction (XRD) Analysis. Figure 2 shows the XRD pattern of $\mathrm{CuO}$ NPs synthesized from copper (II) nitrate trihydrate and Catha edulis leaf extract using three different ratios (w/v). The formation of biosynthesized $\mathrm{CuO}$ NPs was confirmed by X-ray diffraction measurements. The diffraction peaks observed at $2 \theta 31.4876^{\circ}, 35.4894^{\circ}, 38.6974^{\circ}$, $48.7540^{\circ}, 53.4330^{\circ}, 58.2323^{\circ}, 61.5322^{\circ}, 66.2470^{\circ}, 67.6419^{\circ}$, $72.3621^{\circ}$, and $75.2398^{\circ}$ in Figure 2(a), 32.4911 $1^{\circ}, 35.5036^{\circ}$, $36.4007^{\circ}, 38.4007^{\circ}, 48.8047^{\circ}, 53.4321^{\circ}, 58.2223^{\circ}, 61.5010^{\circ}$, $65.7825^{\circ}, 67.9854^{\circ}, 72.3607^{\circ}$, and $75.7198^{\circ}$ in Figure 2(b), and $31.6751^{\circ}, 35.5086^{\circ}, 38.7159^{\circ}, 48.8047^{\circ}, 53.4321^{\circ}, 58.2223^{\circ}$, $61.5010^{\circ}, 66.2656^{\circ}, 67.4820^{\circ}, 72.3607^{\circ}$, and $75.2598^{\circ}$ in Figure 3(c) were corresponding to (100), (002), (200), (202), (020), (202), (113), (022), (020), (311), and (004) crystal planes, respectively, which is in agreement with the previously reported work $[3,17,21,24]$.

The observed diffraction reflections are comparable with JCPDS card № 048-1548, 048-1548, and 048-1548 for each ratio and is attributed to bulk $\mathrm{CuO}$ materials [25]. All diffraction peaks can be indexed as the typical monoclinic structure $\mathrm{CuO}$ NPs. The absence of extra diffraction peaks in the XRD patterns in Figures 2(a) and 2(c) shows the purity of the biosynthesized CuO NPs. However, the appearance of additional diffraction peaks observed in Figure 2(b) at about $2 \theta 36.4^{\circ}$ and $44.9^{\circ}$ (with reference to ICSD file no. 98-0154604) indicates the existence of the $\mathrm{Cu}_{2} \mathrm{O}$ at the surface [35]. Moreover, the well-defined and sharp $\mathrm{CuO}$ reflections observed from XRD patterns confirms the good crystalline nature of the biosynthesized $\mathrm{CuO}$ NPs. Similar results were also reported in previous similar works [19, 27, 36]. The crystal size of the biosynthesized $\mathrm{CuO}$ NPs was calculated using Debye Scherrer's formula. As a result, the crystal sizes of $\mathrm{CuO}$ NPs corresponding to the highest intense peaks for $1: 10,3: 10$, and $1: 2$ were calculated and found to be $28.10 \mathrm{~nm}, 25.30 \mathrm{~nm}$, and $18.20 \mathrm{~nm}$, respectively.

3.3. Scanning Electron Microscopy-Energy-Dispersive Spectroscopy (SEM-EDS) Analysis. The surface morphologies of biosynthesized $\mathrm{CuO}$ NPs were studied by SEM, and the results are presented in Figure 3. Figure 3(a) is a SEM image of $\mathrm{CuO}$ NPs synthesized using 1:10 ratio (w/v) which showed uniform and defined spherical-shaped NPs with low aggregation. The low aggregation could be due to the high fraction of plant extract used which acts as a capping/stabilizing agent. Similar to the 1:10 ratio, Figure 3(b) shows the SEM image of CuO NPs synthesized using $3: 10$ in which the NPs possessed spherical shapes with some aggregation/ agglomeration as the concentration of the plant extract that acts as a stabilizing agent used was decreased relative to the amount of salt precursor used. Furthermore, the SEM image of the biosynthesized $\mathrm{CuO}$ NPs using $1: 2$ ratios (w/v) is also shown in Figure 3(c). As it can be observed, this SEM image showed a similar feature with $\mathrm{CuO}$ NPs synthesized using 1 : 10 and $3: 10$ ratios but with increased aggregation/agglomeration of the NPs. The high aggregation/agglomeration of the NPs may be caused due to polarity and electrostatic attraction of $\mathrm{CuO}$ NPs as the result of increased concentration of the salt precursor [37]. In general, it is noticed from the SEM images analysis that the biosynthesized $\mathrm{CuO}$ NPs showed small and uniform-sized spherical NPs which is in agreement with the previously reported work $[19,35,38]$.

To gain further insight into the features of the biosynthesized $\mathrm{CuO}$ NPs, the chemical composition of the NPs was analyzed using EDS (Figure 4). The energy-dispersive spectra of the samples obtained from the SEM-EDS revealed that the sample prepared by using Catha edulis plant extract has pure $\mathrm{CuO}$ phases. 


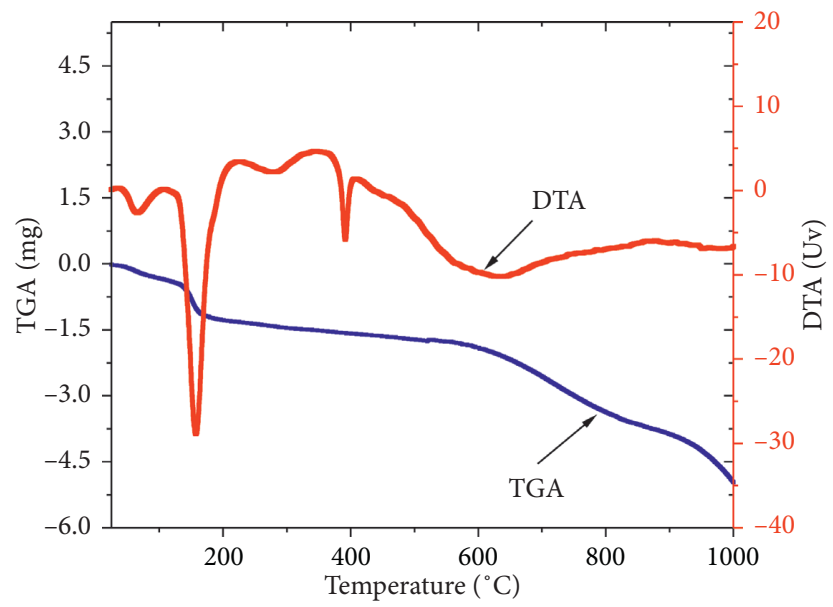

Figure 1: Thermal analysis of as-synthesized CuO NPs using Copper (II) nitrate trihydrate and Catha edulis synthesized using $1: 10$ ratio $(\mathrm{w} / \mathrm{v})$.

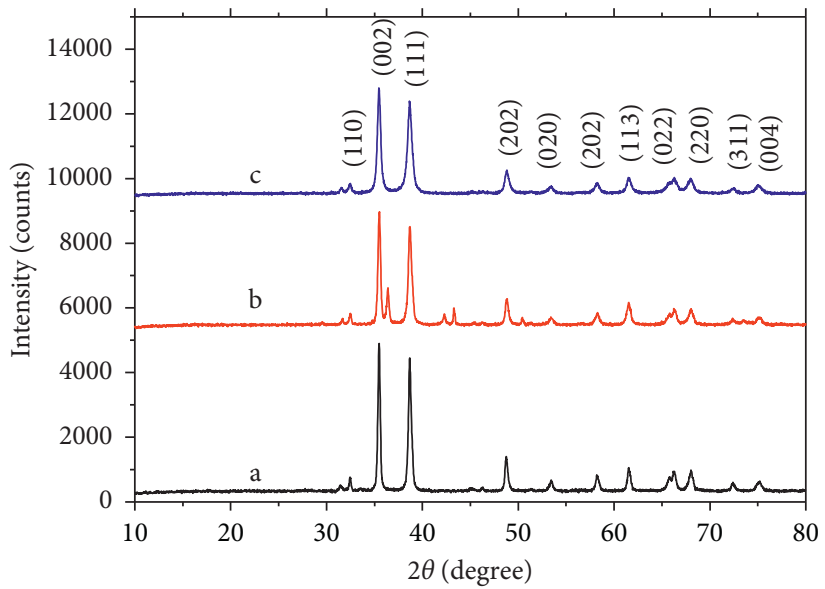

FIGURE 2: XRD patterns of CuO NPs synthesized using copper (II) nitrate trihydrate and Catha edulis leaf extract of different ratios (w/v): (a) $1: 10$, (b) $3: 10$, and (c) $1: 2$.

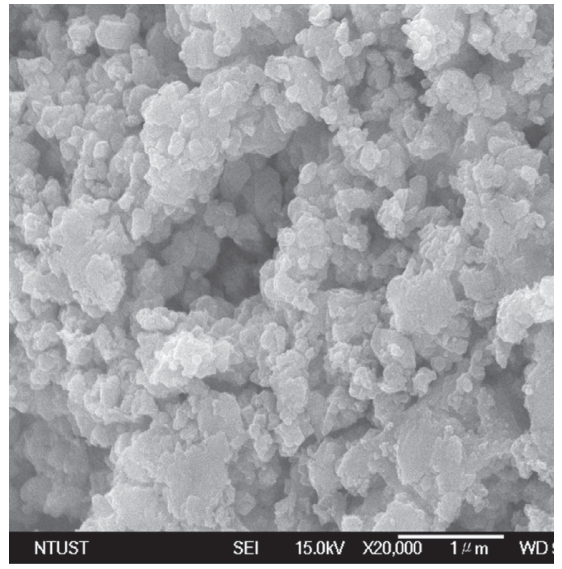

(a)

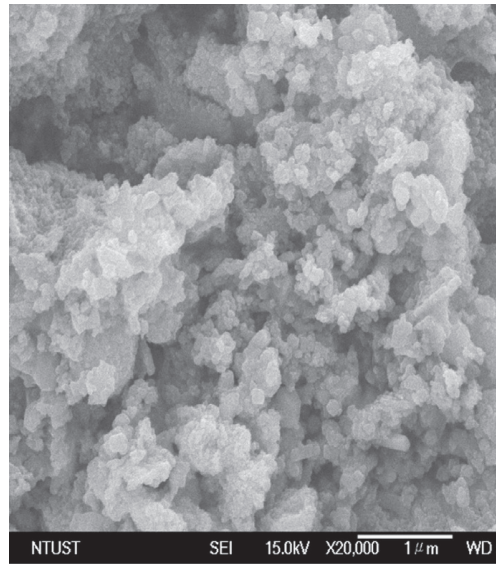

(b)

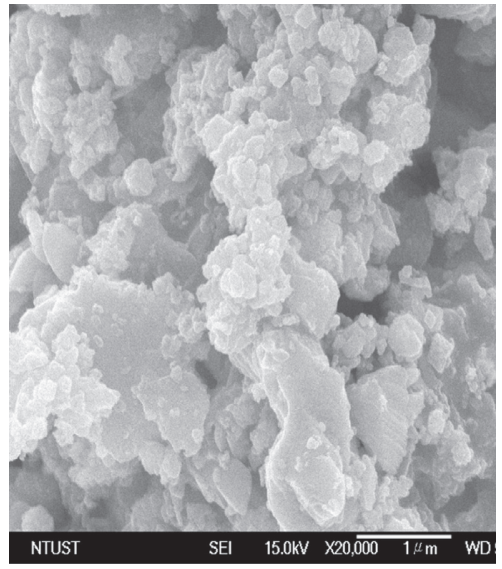

(c)

FIGURE 3: SEM images of CuO NPs synthesized using copper (II) nitrate trihydrate and Catha edulis leaf extract in different ratios (w/v) (a) $1: 10$, (b) $3: 10$, and (c) $1: 2$. 


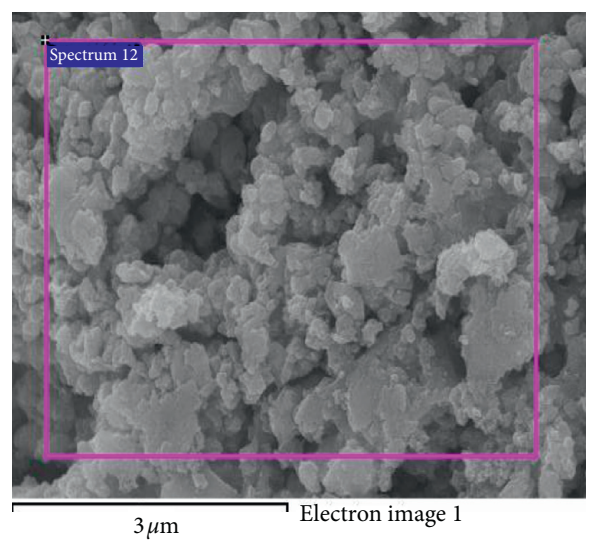

(a)

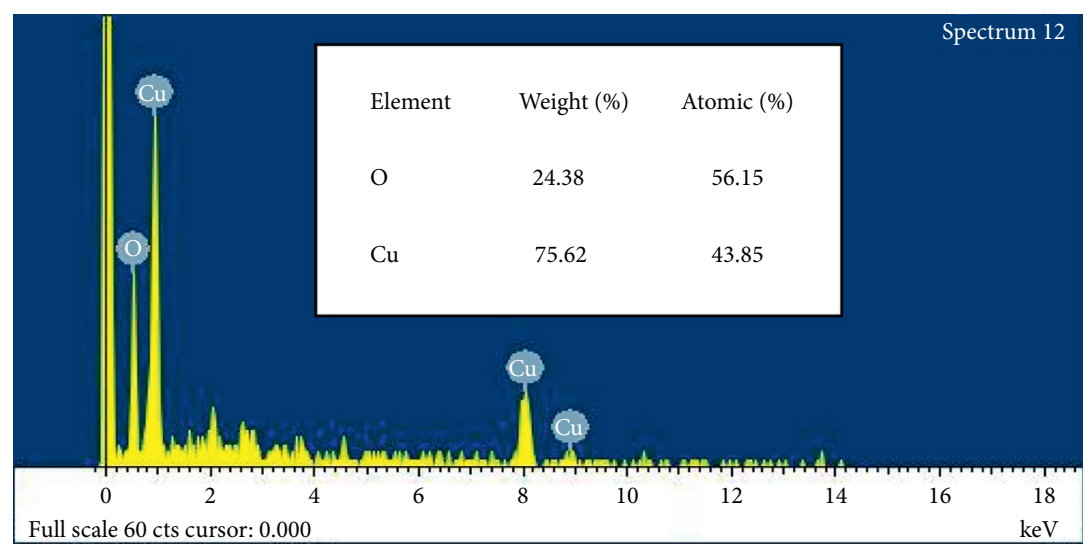

(b)

FIGURE 4: SEM images of the selected area for EDX spectra (a) and quantitative analysis (b) of CuO NPs synthesized using copper (II) nitrate trihydrate and Catha edulis leaf extract in 1:10 ratios $(\mathrm{w} / \mathrm{v})$.

The EDS studies of Figure 4 present three peaks between $1 \mathrm{kV}$ and $10 \mathrm{kV}$ that are directly related to $\mathrm{Cu}$ in the tested material [39]. The results indicate that the reaction product is composed of high purity $\mathrm{CuO}$ NPs which agrees with the result obtained from XRD (Figure 2). The weight composition obtained from EDS analysis of the normalized spectrum was $\mathrm{Cu}(75.62 \%)$ and oxygen (24.38\%). EDS also revealed the formation of nonstoichiometric $\mathrm{CuO}$ NPs with oxygen vacancy which could lead to better antibacterial activity.

\subsection{Transmission Electron Microscope (TEM) Analysis.} Figure 5 shows the TEM images of CuO NPs synthesized using 1:10 ratio. HR-TEM with SAED analysis can be used to understand the crystalline characteristics and size of the synthesized nanoparticles [40]. The TEM image in Figure 5(a) reveals that the biosynthesized $\mathrm{CuO}$ NPs were agglomerated which are interconnected to each other and spherical in shape which is also in agreement with the result obtained from SEM. The crystalline nature of the synthesized $\mathrm{CuO}$ nanoparticle is confirmed by the SAED pattern which is represented by Figure 5(b). The SAED pattern indicates the polycrystalline nature of the prepared $\mathrm{CuO}$ NPs [41]. In general, the results obtained from morphological characterizations analysis (SEM and TEM) confirmed that the biosynthesized $\mathrm{CuO}$ NPs using Catha edulis leaf extract are agglomerated and spherical in shape which is also similar to the previously reported work [42].

3.5. UV-Visible Spectra. Figures 6(a), 6(b), and 6(c) show the UV-Vis spectrum of green synthesized $\mathrm{CuO}$ NPs synthesized using $1: 10,3: 10$, and $1: 2$ ratios, respectively. The biosynthesized $\mathrm{CuO}$ NPs showed high absorbance over the visible wavelength range which is one of the indications that the narrow-band gap $\mathrm{CuO}$ NPs were successfully synthesized [35].

As shown in Figure 7, the band gap values of the $\mathrm{CuO}$ NPs were determined by analyzing the optical data with the expression for the optical absorbance $\alpha$ and the photon energy $h v$ using Tauc's plot [43].

$$
\alpha h v=A(h-E g)^{n / 2 n},
$$

where $\alpha$ is the absorption coefficient, which is proportional to the absorbance, $h$ is Planck's constant $(J \cdot s), v$ is the light frequency $\left(\mathrm{s}^{-1}\right), A$ is the absorbance, $E_{g}$ is the bandgap energy, and $n$ is a constant related to the electronic interband transition.

The band gaps of the CuO NPs were, then, determined by extrapolating the straight line portion of the $(\alpha h v)^{2}$ versus $(h v)$ graphs to the $(h v)$ axis until $(\alpha h v)^{1 / n}=0$. Based on Tauc's plot, the bandgaps of synthesized $\mathrm{CuO}$ NPs with ratios $1: 10,3: 10$, and $1: 2$ were obtained to be $1.31,1.39$, and $1.45 \mathrm{eV}$, respectively. These findings are similar with previous reports made on $\mathrm{CuO}$ nanoparticles [35].

3.6. Fourier Transform Infrared Spectroscopy. Figures 8(a) and 8(b) show the FTIR spectra of as-synthesized and calcinated $\mathrm{CuO}$ NPs. Based on the FTIR spectrum of $\mathrm{CuO}$ NPs, the most significant absorption peaks were those observed at 531 and $603 \mathrm{~cm}^{-1}$ that correspond to the stretching vibration of the $\mathrm{Cu}-\mathrm{O}$ bond in monoclinic $\mathrm{CuO}$ which is in close agreement with the previously reported work [20]. The strong peaks at 1030 and $1053 \mathrm{~cm}^{-1}$ were due to C-O stretching vibration in the carboxylic group and flavanones. The characterized peaks observed at $1383 \mathrm{~cm}^{-1}$ were due to $\mathrm{C}-\mathrm{N}$ stretching vibration in the amine group [44]. The strong bands at 1604 and $1638 \mathrm{~cm}^{-1}$ were due to aromatic $\mathrm{C}=\mathrm{C}$ bending vibration, and absorption peaks at $2875 \mathrm{~cm}^{-1}$ and $2884 \mathrm{~cm}^{-1}$ were attributed to the asymmetric and symmetric $\mathrm{C}-\mathrm{H}$ stretching mode caused by the phenolic compounds [24]. The broad band at $3439 \mathrm{~cm}^{-1}$ was due to $\mathrm{O}-\mathrm{H}$ stretching vibration in alcohols. The presence of these biologically active plant compounds might have been responsible for the reduction and capping of $\mathrm{CuO}$ NPs. These results were similar to the previous report on the synthesis of $\mathrm{CuO}$ NPs using different plant extracts $[7,17]$.

3.7. Antibacterial Activity. The antibacterial activity of the biosynthesized $\mathrm{CuO}$ NPs was determined by using the disk diffusion method against Gram-positive and Gram-negative 


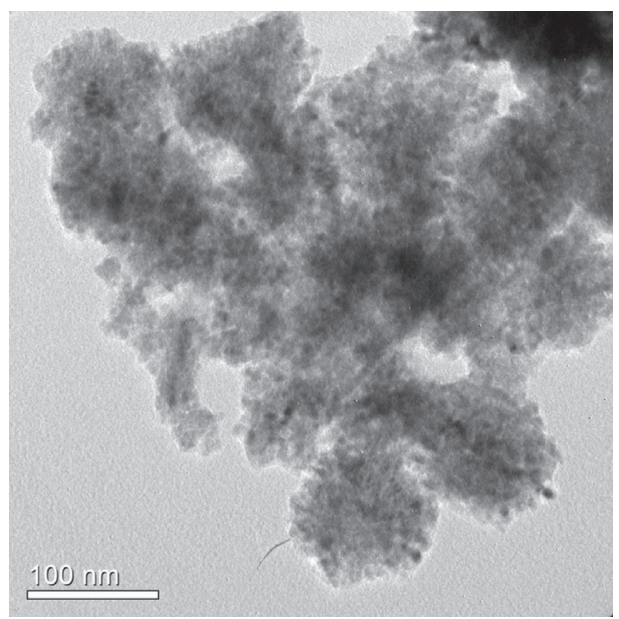

(a)

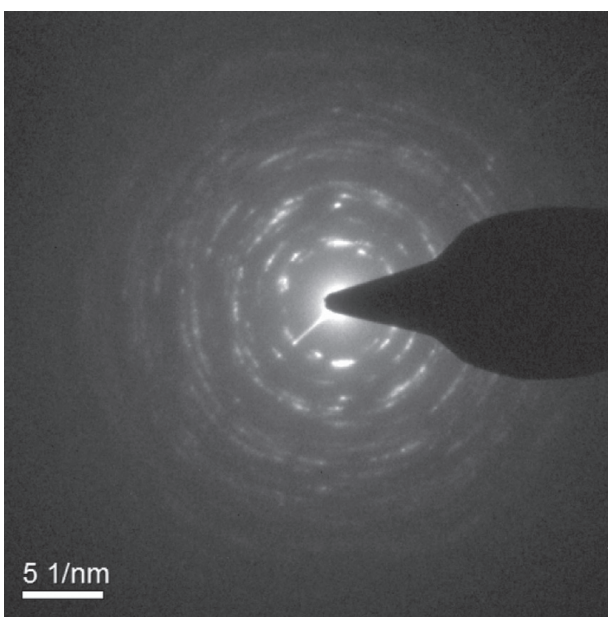

(b)

Figure 5: (a) TEM image and (b) SAED pattern of biosynthesized CuO NPs from copper (II) nitrate trihydrate and leaf extract of Catha edulis in $1: 10$ ratio $(\mathrm{w} / \mathrm{v})$.

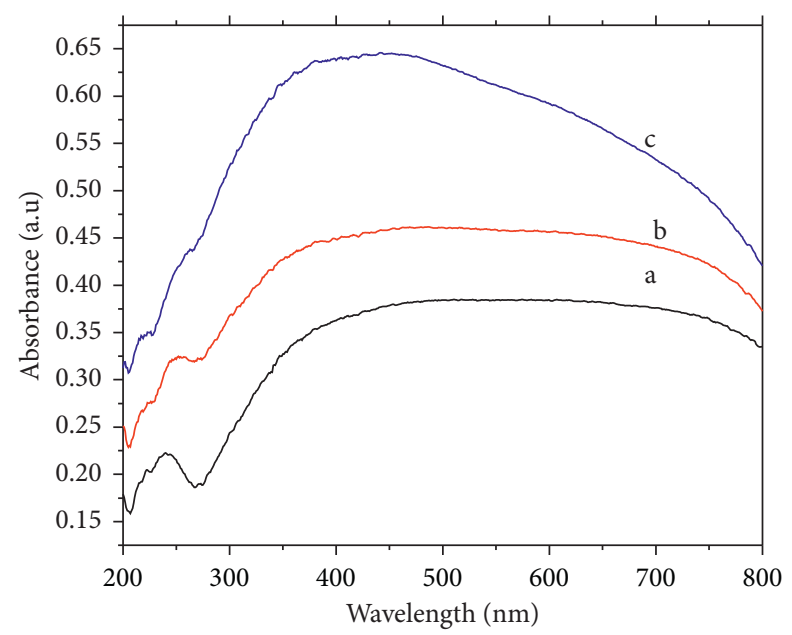

FIGURE 6: UV-V is spectra of CuO NPs synthesized using copper (II) nitrate trihydrate and Catha edulis leaf extract in (a) $1: 10$, (b) $3: 10$, and (c) $1: 2$ ratios $(\mathrm{w} / \mathrm{v})$.

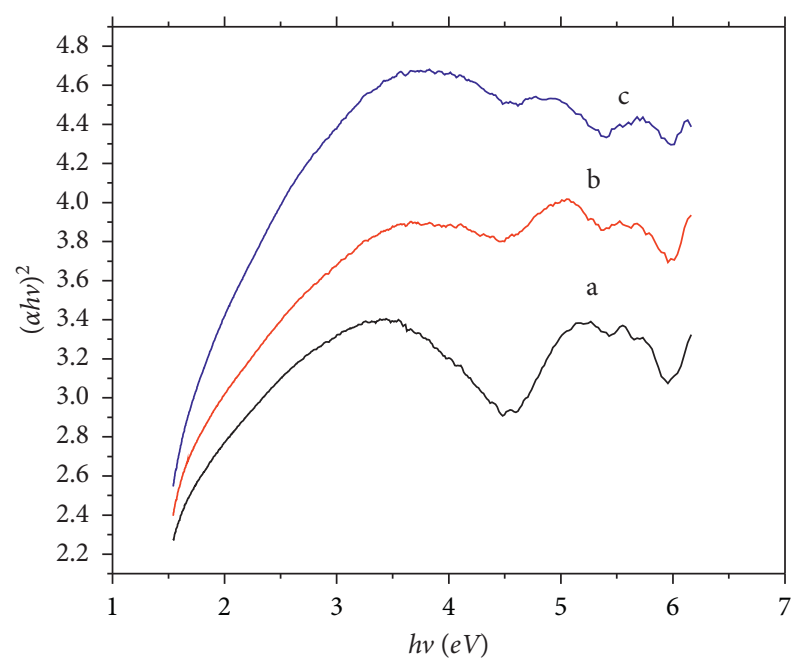

Figure 7: Tauc plots of CuO NPs synthesized using copper (II) nitrate trihydrate and Catha edulis leaf extract in (a) $1: 10$, (b) $3: 10$, and (c) $1: 2$ ratios $(\mathrm{w} / \mathrm{v})$. 


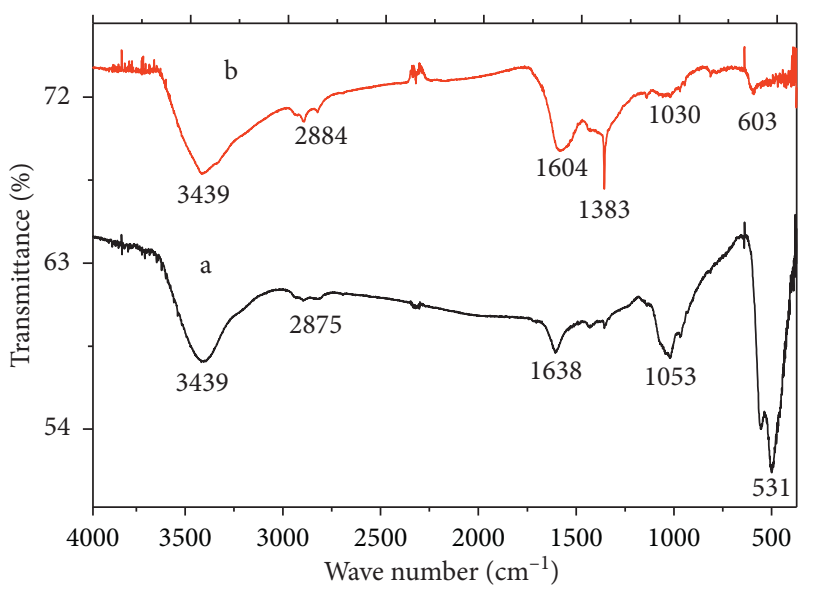

FIGURE 8: FTIR spectra of (a) calcinated and (b) as-synthesized CuO NPs synthesized from copper (II) nitrate trihydrate and leaf extract of Catha edulis in $1: 10$ ratio $(\mathrm{w} / \mathrm{v})$.

bacterial strains. Table 1 shows antibacterial activities of $20 \mathrm{mg} / \mathrm{mL}$ and $40 \mathrm{mg} / \mathrm{mL}$ of biosynthesized $\mathrm{CuO}$ NPs against the selected bacterial strains $S$. aureus, S. pyogenes, E. coli, and K. pneumonia. Each experiment was repeated three times, and the resulting bacterial growths on three plates corresponding to a particular sample were reported as the mean \pm standard deviation $(n=3)$. CuO NPs synthesized using $1: 2$ ratios for both concentrations used showed high antibacterial activity against all bacterial strains compared to $\mathrm{CuO}$ NPs synthesized using $1: 10$ and 3:10 ratios. This is most probably due to the small size it possessed compared to others that led to high penetration ability and causing fast cell damage. Furthermore, as the concentration of the NPs increased, the antibacterial activity was also improved that agrees with the previous report [45].

The findings of this study also revealed that Grampositive bacterial strains were less sensitive than Gramnegative strains against the biosynthesized $\mathrm{CuO}$ NPs. The opposite charges that exist on bacterial strains and copper ions released from NPs are thought to cause adhesion and enhance bioactivity due to electrostatic forces. As a result, since peptidoglycans are negatively charged molecules, they bind with $\mathrm{Cu}^{2+}$ ions released from $\mathrm{CuO}$ NPs in a liquid growth medium. Another proposed mechanism is that copper ions released from the NPs may attach to the negatively charged bacterial cell wall and rupture it leading to protein denaturation and cause cell death. The Gram-negative bacterial strains, E. coli and K. pneumoni, may allow more $\mathrm{Cu}^{2+}$ ions to reach the plasma membrane. However, the previous report showed that Gram-negative bacterial strains (E. coli and K. pneumonia) were found less susceptible to antibiotics and antibacterial agents than Grampositive bacteria (S. aureus and S. pyogen) $[46,47]$. Since NPs may be smaller in size than bacterial pores, the NPs could have a unique ability to penetrate the cell membrane and cause cell death of the bacterial strains which may be the case for $\mathrm{CuO}$ NPs $[1,48]$. The antimicrobial activities of Catha edulis extract obtained from the aqueous solution against the selected bacterial species were also tested. The zones of inhibitions measured against this aqueous extract were
Table 1: Antibacterial activity of CuO NPs on selected pathogenic bacterial strains.

\begin{tabular}{|c|c|c|c|c|}
\hline Treatment & S. aureus & S. pyogenes & E. coli & K. pneumonia \\
\hline $\begin{array}{l}\text { CuO } 1: 10 \text { ratio } \\
(20 \mathrm{mg} / \mathrm{mL})\end{array}$ & $6 \pm 0.02$ & $6 \pm 0.02$ & $9 \pm 0.03$ & $8 \pm 0.01$ \\
\hline $\begin{array}{l}\mathrm{CuO} 3: 10 \text { ratio } \\
(20 \mathrm{mg} / \mathrm{mL})\end{array}$ & $7 \pm 0.04$ & $6 \pm 0$ & $10 \pm 0.02$ & $9 \pm 0.04$ \\
\hline $\begin{array}{l}\mathrm{CuO} 1: 2 \text { ratio } \\
(20 \mathrm{mg} / \mathrm{mL})\end{array}$ & $9 \pm 0.01$ & $9 \pm 0.02$ & $12 \pm 0.05$ & $11 \pm 0.03$ \\
\hline $\begin{array}{l}\mathrm{CuO} 1: 10 \text { ratio } \\
(40 \mathrm{mg} / \mathrm{mL})\end{array}$ & $16 \pm 0.04$ & $18 \pm 0.01$ & $21 \pm 0.03$ & $19 \pm 0.01$ \\
\hline $\begin{array}{l}\mathrm{CuO} 3: 10 \text { ratio } \\
(40 \mathrm{mg} / \mathrm{mL})\end{array}$ & $18 \pm 0$ & $20 \pm 0.03$ & $29 \pm 0.02$ & $28 \pm 0.04$ \\
\hline $\begin{array}{l}\mathrm{CuO} 1: 2 \text { ratio } \\
(40 \mathrm{mg} / \mathrm{mL})\end{array}$ & $22 \pm 0.01$ & $24 \pm 0.02$ & $32 \pm 0.02$ & $29 \pm 0.03$ \\
\hline Catha edulis & 17 & 29 & 22 & 16 \\
\hline $\begin{array}{l}\text { Gentamicin } \\
\text { (+ve control) }\end{array}$ & 22 & 22 & 22 & 22 \\
\hline $\begin{array}{l}\text { DMSO (-ve } \\
\text { control) }\end{array}$ & - & - & - & - \\
\hline
\end{tabular}

$17 \mathrm{~mm}, 29 \mathrm{~mm}, 22 \mathrm{~mm}$, and $16 \mathrm{~mm}$ for $S$. aureus, $S$. pyogenes, E. coli, and K. pneumonia, respectively. The result showed that Catha edulis extracted were more active against the positive bacterial strain, S. pyogenes [49].

\section{Conclusions}

Biosynthesis of $\mathrm{CuO}$ NPs using Catha edulis leaves extract and copper (II) nitrate trihydrate in an aqueous medium, characterizations of the synthesized NPs, and their bioassay against the selected drug resistant bacterial strains were successfully carried out. The biosynthesized $\mathrm{CuO}$ NPs were extensively characterized using different characterization techniques. The morphological features of the biosynthesized $\mathrm{CuO}$ NPs were characterized by SEM and TEM. According to these morphological analyses, the biosynthesized $\mathrm{CuO}$ NPs consisted of uniformly distributed spherical-shaped particles in aggregated form. The crystallinity and crystal structure of the synthesized NPs were characterized using the XRD technique. According to the 
findings from XRD, the biosynthesized $\mathrm{CuO}$ NPs were highly crystalline and were found to be pure. The crystal size of the synthesized $\mathrm{CuO}$ NPs was also determined from the XRD pattern using the Scherrer equation and was found to be $28.10 \mathrm{~nm}, 25.30 \mathrm{~nm}$, and $18.20 \mathrm{~nm}$ for $1: 10,3: 10$, and 1 : 2 ratios, respectively confirming that nanosized particles were synthesized. The antibacterial activities of the synthesized $\mathrm{CuO}$ NPs against Gram-negative (K. pneumonia and E. coli) and Gram-positive (S. aureus and S. pyogenes) bacterial strains were evaluated by measuring the zone of inhibition and were found to be promising against the selected bacterial strains. Accordingly, $\mathrm{CuO}$ NPs synthesized in $1: 2$ ratios with smaller crystal size $(18.2 \mathrm{~nm})$ showed high antibacterial activities against all bacterial strains, and the zone of inhibitions were found to be $22 \mathrm{~mm}, 24 \mathrm{~mm}, 32 \mathrm{~mm}$, and $29 \mathrm{~mm}$ against bacterial strains K. pneumonia, E.coli, $S$. aures, and $S$. pyogenes, respectively.

\section{Data Availability}

The data used to support the findings of this study are available from the corresponding author upon request.

\section{Conflicts of Interest}

The authors declare that they have no conflicts of interest.

\section{Acknowledgments}

The authors acknowledge Adama Science and Technology University (ASTU) for supporting this project through ASTU's 12 cycle research grant successfully. The authors extend their thanks to the Department of Applied Chemistry and Department of Materials Science and Engineering at Adama Science and Technology University for providing facilities such as the UV-Visible spectrophotometer, thermal Analyzer, and XRD. The Department of Chemistry at Addis Ababa University is also thanked by the authors for FTIR characterization. Furthermore, the authors duly acknowledge National Twain Science and Technology University, Department of Materials Science and Engineering, Twain, for SEM, EDX, and TEM data generation. This research work was supported by Adama Science and Technology University through its $12^{\text {th }}$ cycle research grant. The funder, Adama Science Technology University, has not been involved in editing, approval, or decision to publish this manuscript. The authors declare that the funder has no issue of conflicts of interest with authors concerning submission and publication of this research work.

\section{References}

[1] D. Rania, A. Rabah, T. Mamadou, M. Christine, and K. Andrei, "Antibacterial activity of $\mathrm{ZnO}$ and $\mathrm{CuO}$ nanoparticles against gram positive and gram negative strains," Journal of Materials Science \& Engineering C, vol. 104, pp. 1-9, 2019.

[2] H. R. Naika, K. Lingaraju, K. Manjunath et al., "Green synthesis of $\mathrm{CuO}$ nanoparticles usingGloriosa superbaL. extract and their antibacterial activity," Journal of Taibah University for Science, vol. 9, no. 1, pp. 7-12, 2015.

[3] A. Maqusood, A. A. Hisham, M. A. Majeed, K. Ponmurugan, and A. A. Naif, "Synthesis, characterization, and antimicrobial activity of copper oxide nanoparticles," Journal of Nanomaterials, vol. 2014, Article ID 637858, 4 pages, 2014.

[4] P. Yugandhar, T. Vasavi, P. Uma Maheswari Devi, and N. Savithramma, "Bioinspired green synthesis of copper oxide nanoparticles from Syzygium alternifolium (Wt.) Walp: characterization and evaluation of its synergistic antimicrobial and anticancer activity," Applied Nanoscience, vol. 7, no. 7, pp. 417-427, 2017.

[5] R. Javed, M. Ahmed, I. u. Haq, S. Nisa, and M. Zia, "PVP and PEG doped $\mathrm{CuO}$ nanoparticles are more biologically active: antibacterial, antioxidant, antidiabetic and cytotoxic perspective," Materials Science and Engineering: C, vol. 79, pp. 108-115, 2017.

[6] G. D. Meron, K. S. Fedlu, D. E. Gemechu, and A. G. Bedasa, "Synthesis of zinc oxide nanoparticles using leaf extract of lippia adoensis (koseret) and evaluation of its antibacterial activity," Journal of Chemistry, vol. 2020, Article ID 7459042, 9 pages, 2020.

[7] D. Vaidehi, V. Bhuvaneshwari, B. Devaraj, and B. PavithraSheetal, "Antibacterial and photocatalytic activity of copper oxide nanoparticles synthesized using Solanum lycopersicum leaf extract," Materials Research Express, vol. 5, pp. 3-4, 2018.

[8] M. Mortimer, K. Kasemets, and A. Kahru, "Toxicity of $\mathrm{ZnO}$ and $\mathrm{CuO}$ nanoparticles to ciliated protozoa Tetrahymena thermophila," ToxicologyTetrahymena Thermophila, vol. 269, no. 2-3, pp. 182-189, 2010.

[9] G. Q. Yuan, H. F. Jiang, C. Lin, and S. J. Liao, "Shape and sizecontrolled electrochemical synthesis of cupric oxide nanocrystals," Journal of Crystal Growth, vol. 303, pp. 400-406, 2015.

[10] R. Ranjbar-Karimi, A. Bazmandegan-Shamili, A. Aslani, and K. Kaviani, "Sonochemical synthesis, characterization and thermal and optical analysis of $\mathrm{CuO}$ nanoparticles," Physica B: Condensed Matter, vol. 405, no. 15, pp. 3096-3100, 2010.

[11] M. Suleiman, M. Mousa, A. Hussein, B. Hammouti, T. B. Hadda, and I. Warad, "Copper (II)-oxide nanostructures: synthesis, characterizations and their applications-review," Journal of Materials and Environmental Science, vol. 4, no. 5, pp. 792-797, 2013.

[12] C. Karunakaran, G. Manikandan, and P. Gomathisankar, "Microwave, sonochemical and combustion synthesized $\mathrm{CuO}$ nanostructures and their electrical and bactericidal properties," Journal of Alloys and Compounds, vol. 580, pp. 570-577, 2013.

[13] R. Katwal, H. Kaur, G. Sharma, M. Naushad, and D. Pathania, "Electrochemical synthesized copper oxide nanoparticles for enhanced photocatalytic and antimicrobial activity," Journal of Industrial and Engineering Chemistry, vol. 31, pp. 173-184, 2015.

[14] Q. Zhang, K. Zhang, D. Xu et al., "CuO nanostructures: synthesis, characterization, growth mechanisms, fundamental properties, and applications," Progress in Materials Science, vol. 60 , pp. 208-337, 2014.

[15] A. B. Devi, D. S. Moirangthem, N. C. Talukdar, M. D. Devi, N. R. Singh, and M. N. Luwang, "Novel synthesis and characterization of $\mathrm{CuO}$ nanomaterials: biological applications," Chinese Chemical Letters, vol. 25, no. 12, pp. 1615-1619, 2014. 
[16] Z. N. Kayani, M. Umer, S. Riaz, and S. Naseem, "Characterization of copper oxide nanoparticles fabricated by the solgel method," Journal of Electronic Materials, vol. 44, no. 10, pp. 3704-3709, 2015.

[17] S. Selvam, V. Seerangaraj, B. Devaraj et al., "Biogenesis of copper oxide nanoparticles using Sida acuta and their incorporation over cotton fabrics to prevent the pathogenicity of Gram negative and Gram positive bacteria," Journal of Photochemistry and Photobiology, B: Biology, vol. 188, pp. 126-134, 2018.

[18] M. Hosseini-Koupaei, B. Shareghi, A. A. Saboury et al., "Catalytic activity, structure and stability of proteinase $\mathrm{K}$ in the presence of biosynthesized $\mathrm{CuO}$ nanoparticles," International JournalInternational Journal of Biological MacromoleculesMacromolecules, vol. 122, pp. 732-744, 2019.

[19] T. Shima, K. Mahshid, and A. Shokouh, "Green synthesis and morphology dependent antibacterial activity of copper oxide nanoparticles," Journal of Nanostructure, vol. 9, pp. 163-171, 2018.

[20] D. Berraa, S. Laouinia, B. Benhaouab, M. Ouahrania, D. Berrania, and A. Rahald, "Green synthesis of copper oxide nanoparticles by pheonix dactylifera leaves extract," Digest Journal of Nanomaterials and Biostructures, vol. 13, pp. 1231-1238, 2018.

[21] R. Sivaraj, P. K. S. M. Rahman, P. Rajiv, S. Narendhran, and R. Venckatesh, "Biosynthesis and characterization of Acalypha indica mediated copper oxide nanoparticles and evaluation of its antimicrobial and anticancer activity," Spectrochimica Acta Part A: Molecular and Biomolecular Spectroscopy, vol. 129, pp. 255-258, 2014.

[22] N. P. S. Acharyulu, R. S. Dubey, V. Swaminadham, R. L. Kalyani Pratap Kollu, and S. V. N. Pammi, "Green synthesis of $\mathrm{CuO}$ nanoparticles using Phyllanthus amarus leaf extract and their antibacterial activity against multidrug resistance bacteria," International Journal of Engineering Research \& Technology, vol. 3, pp. 255-258, 2014.

[23] S. Yallappa, J. Manjanna, M. A. Sindhe, N. D. Satyanarayan, S. N. Pramod, and K. Nagaraja, "Microwave assisted rapid synthesis and biological evaluation of stable copper nanoparticles using T. arjuna bark extract," Spectrochimica Acta Part A: Molecular and Biomolecular Spectroscopy, vol. 110, pp. 108-115, 2013.

[24] K. S. Jitendra, M. A. Shaheer, S. Ameen, S. Pratibha, and S. Gurdip, "Green synthesis of $\mathrm{CuO}$ nanoparticles with leaf extract of Calotropisgigantea and its dye-sensitized solar cells applications," Journal of Alloys and Compounds, vol. 632, pp. 321-325, 2015.

[25] A. M. Awwad, B. A. Albiss, and N. M. Salem, "Antibacterial activity of synthesized copper oxide nanoparticles using Malva sylvestris leaf extract," Sikkim Manipal University Medical Journal, vol. 2, pp. 18-25, 2015.

[26] A. Y. Jayalakshmi, "Green synthesis of copper oxide nanoparticles using aqueous extract of flowers of Cassia alata and particles characterization," International Journal of Nanomaterials and Biostructures, vol. 4, pp. 66-71, 2014.

[27] R. Sankar, P. Manikandan, V. Malarvizhi, T. Fathima, K. S. Shivashangari, and V. Ravikumar, "Green synthesis of colloidal copper oxide nanoparticles using Carica papaya and its application in photocatalytic dye degradation," Spectrochimica Acta Part A: Molecular and Biomolecular Spectroscopy, vol. 121, pp. 746-750, 2014.

[28] M. M. Elhassan, S. I. Abdelwahab, and R. Al-sanousi, "In vitro hepatotoxcity of Catha edulisForsk. (Khat) phenolic-rich extract on human hepatocytes," Journal of Applied Pharmaceutical Science, vol. 4, pp. 42-46, 2014.

[29] M. Berhanu, E. Aregash, and M. Alyi, "Socio-economic impact of khat in mana district, jimma zone, south western Ethiopia," Discourse Journal of Agriculture and Food Sciences, vol. 2, pp. 21-32, 2014.

[30] N. Tyler, K. Proma, and G. Simon, "The psychostimulant drug khat (Catha edulis): a mini-review," Phytochemistry Letters, vol. 13, pp. 127-133, 2015.

[31] G. Kiflom, H. K. Mebrahtu, and A. Muluken, "Green synthesis of $\mathrm{CuO}$ nanoparticles using leaf extract of Catha edulis and its antibacterial activity," Journal of Pharmacy and Pharmacology, vol. 7, pp. 327-342, 2019.

[32] N. Mahmoud, S. Mohammad, and R. V. Akbar, "Green synthesis of $\mathrm{CuO}$ nanoparticles by aqueous extract of Anthemis nobilis flowers and their catalytic activity for the $\mathrm{A}^{3}$ coupling reaction," Journal of Colloid and Interface Science, vol. 459, pp. 183-188, 2015.

[33] N. Sundaramurthy and C. Parthiban, "Biosynthesis of copper oxide nanoparticles using Pryus Pyrifolialeaf extract and evolve the catalytic activity," International Research Journal of Engineering and Technology, vol. 2, pp. 332-338, 2015.

[34] V. Anuradha, P. Shankar, P. Bhuvan, A. M. Syed, and N. Yogananth, "Terminalia Arjunabark assisted biosynthesis, characterization and bioactivity of metal oxide nanoparticles," Journal of Chemical and Pharmaceutical Research, vol. 9, pp. 34-46, 2017.

[35] I. Faheem, S. Sammia, A. K. Shakeel, A. Waqar, and Z. Sabah, "Green synthesis of copper oxide nanoparticles using $\mathrm{Abu}$ tilon indicum leaf extract: antimicrobial, antioxidant and photocatalytic dye degradation activities," Tropical Journal of Pharmaceutical Research, vol. 16, pp. 743-753, 2017.

[36] H. M. M. Ibrahim, "Green synthesis and characterization of silver nanoparticles using banana peel extract and their antimicrobial activity against representative microorganisms," Journal of Radiation Research and Applied Sciences, vol. 8, no. 3, pp. 265-275, 2015.

[37] V. Sekar, V. Baskaralingam, M. Balasubramanian, and S. Malaikkarasu, "Laurusnobilis leaf extract mediated green synthesis of $\mathrm{ZnO}$ nanoparticles: characterization and biomedical applications," Biomedicine \& Pharmacotherapy, vol. 84, p. 1213, 2016.

[38] Y. Aparna, K. V. Enkateswara Rao, and P. Srinivasa Subbarao, "Synthesis and characterization of $\mathrm{CuO}$ nanoparticles by novel sol gel method," Journal of Environmental Science and Biotechnology, vol. 48, pp. 30-33, 2016.

[39] A. P. Angeline Mary, A. Thaminum Ansari, and R. Subramanian, "Sugarcane juice mediated synthesis of copper oxide nanoparticles, characterization and their antibacterial activity," Journal of King Saud University - Science, vol. 31, no. 4, pp. 1103-1114, 2019.

[40] A. Muthuvel, M. Jothibas, and C. Manoharan, "Effect of chemically synthesis compared to biosynthesized ZnO-NPs using Solanum nigrum leaf extract and their photocatalytic, antibacterial and in-vitro antioxidant activity," Journal of Environmental Chemical Engineering, vol. 8, no. 2, Article ID 103705, 2020.

[41] S. Vijayakumar, P. Arulmozhi, N. Kumar, B. Sakthivel, S. Prathip Kumar, and P. K. Praseetha, "Acalypha fruticosa L. leaf extract mediated synthesis of $\mathrm{ZnO}$ nanoparticles: characterization and antimicrobial activities," Materials Today: Proceedings, vol. 23, p. 73, 2020.

[42] K. Abdullah, J. Mustapha, K. Marwan, and H. Raed, "Facile synthesis of copper oxide nanoparticles via electrospinning," 
Journal of Nanomaterials, vol. 2014, Article ID 438407, 18 pages, 2014.

[43] Z. Zou, Y. Qiu, C. Xie et al., "CdS/TiO2 nanocomposite film and its enhanced photoelectric responses to dry air and formaldehyde induced by visible light at room temperature," Journal of Alloys and Compounds, vol. 645, pp. 17-23, 2015.

[44] A. N. S. Rao and V. T. Venkatarangaiah, "The effect of ceyltrimethylammonium bromide on size and morphology of $\mathrm{ZnO}$ and $\mathrm{CuO}$," Journal of Electrochemical Science and Engineering, vol. 4, pp. 97-110, 2014.

[45] G. Ren, D. Hu, E. W. C. Cheng, M. A. Vargas-Reus, P. Reip, and R. P. Allaker, "Characterisation of copper oxide nanoparticles for antimicrobial applications," International Journal of Antimicrobial Agents, vol. 33, no. 6, pp. 587-590, 2009.

[46] B. Sadeghi, A. Rostami, and S. S. Momeni, "Facile green synthesis of silver nanoparticles using seed aqueous extract of Pistacia atlantica and its antibacterial activity," Spectrochimica Acta Part A: Molecular and Biomolecular Spectroscopy, vol. 134, pp. 326-332, 2015.

[47] A. Mai-Prochnow, M. Clauson, and J. Hong, "New developments in macrolides: structures and antibacterial and prokinetic activities," Journal of Applied Pharmaceutica, vol. 3, pp. 10-14, 2016.

[48] M. Ahamed, H. A. Alhadlaq, M. Khan, P. Karuppiah, and N. A. Al-Dhabi, "Synthesis, characterization, and antimicrobial activity of copper oxide nanoparticles," Journal of Nanomaterial, vol. 2014, p. 17, Article ID 637858, 2014.

[49] A. Elizabath, S. Mythili, and A. Sathiavelu, "Synthesis of silver nanoparticles from the medicinal plant bauhinia acuminata and biophytum sensitivum a comparative study of its biological activities with plant extract," Journal of Applied Pharmaceutical Science, vol. 9, pp. 22-29, 2017. 